\title{
- Door to Door Survey cum Health Camp in Tribal Population of Northern India IJCRR \\ Section: Healthcare
}

Sci. Journal

Impact Factor 4.016 ICV: $\mathbf{7 1 . 5 4}$

\section{S. Muhammad Salim Khan', Ruqia Quansar ${ }^{2}$, Sheikh Mohd Saleem ${ }^{3}$}

'Head \& Associate professor, Department of SPM, Government Medical College, Srinagar; 2Post graduate Scholar, Department of SPM, Government Medical College, Srinagar; ${ }^{3}$ Post Graduate Scholar, Department of Community Medicine, Government Medical College, Srinagar, $] \& K$, India.

\section{ABSTRACT}

Context: In India, a Sub-Centre is the most peripheral and the lowest rung of the three-tier health care delivery system. As part of the various services offered by the Sub-Centre, Door to door surveys and field camp are important activities that bring the health care system to the door step of the community. Door to door surveys and health camps in the adjoining areas of Sub-centres which are located in backward, far flung or tribal areas is a good method to reach the tribal population in particular.

Methods and Material: The door to door survey cum health camp which was conducted by the department of community medicine in collaboration with NSS in the field practise area of Government Medical College, Srinagar. With an intention to organise the health camp for the tribal population, Sub-Centre Faqeer Gujree was selected purposively so as to evaluate the health standards of the tribal population in particular.

Results: Socio-demographic characteristics of the community subject's show male predominant population with a ratio of 89 women to 100 men. $40 \%$ of the population is illiterate and only $4 \%$ individuals having acquired education above higher secondary. $90 \%$ of the total households belong to upper lower to upper middle class socioeconomic status. The community has 247 eligible couples with 23 pregnant women. Total births in the year 2016 were $40.30 \%$ of the population uses contraceptive methods for birth spacing with $100 \%$ immunization coverage in the area. Crude death rate of the area is 4.71 per 1000 population and infant mortality rate is 50.00 per 1000 live births with 9.83 per 1000 population as hospitalization ratio. Conclusions: Door to door surveys is a good method to reach the tribal community in particular and such surveys should be carried out every year to determine the health status and health care delivery services provided to the tribal community.

Key Words: Tribal health, Door to door survey, Health camp, Northern India, Sub-centre

\section{INTRODUCTION}

In India, a Sub-Centre (SC) is the most peripheral and the lowest rung of the three-tier health care delivery system.[1] The subcentre caters 5000 population in plains and 3000 in hilly and tribal areas as per the population norms.[1] Auxiliary Nurse Midwives (ANMs)/Female multipurpose health workers (FMPHW) are the key health field level workers who operate from the Sub-Centres and deliver services related to prevention and control of the disease.[1] Health workers at the sub-centre have the responsibility to encompass preventive, promotive, curative and rehabilitative health care services. These workers act as an interface between the needs of the community and services provided to them. As part of the various services offered by the Sub-Centre, Door to door surveys and field camp are important activities that bring the health care system to the doorstep of the community.[1] Conducting door to door surveys and interviewing the tribal population is not an easy task, as the team faces multiple challenges. The physical demand of travelling long distances over rough terrain and interpersonal challenges of interviewing tribal people can be even more daunting, but for collecting health and environment-related information in tribal areas, door to door surveys are regarded as a valuable tool based on community participatory research principles. [2] The door to door surveys and health camps in the adjoining areas of Sub-centres which are located in backward, far-flung or tribal areas is a good method to reach the tribal population in particular.[2] This will help us in knowing the health standards of the people living in tribal areas as the tribal population has an ethnic, traditional \& cultural identity, distinctive language, they are economically backward

\section{Corresponding Author:}

Dr. S. Muhammad Salim Khan, Head \& Associate Professor, Department of SPM, Government Medical College, Srinagar. Mobile: 9419013699; Email: smsalimkhan2@gmail.com
ISSN: 2231-2196 (Print)
ISSN: 0975-5241 (Online)
DOI: http://dx.doi.org/10.7324/IJCRR.2017.9117

Received: 15.04 .2017

Revised: 08.05.2017

Accepted: 28.05 .2017 
and live in seclusion governed by their own social norm and largely having a self-contained economy.[3] The health problems prevailing in the tribal areas may be due to sociocultural norms of practicing ancient heath practices, use of herbal medicines, taboos \& superstition. Environmental conditions like forest dwelling may pose a risk of vector-borne diseases. Tribal people are reluctant to adapt maternal and child health services, Nutritional problems are common and there is inaccessibility to safe drinking water and sanitation. So there is a need to direct more health attention towards this group of population in order to improve the health status of the community as a whole. Department of community medicine in partnership with National Sample Survey (NSS) conducted a health care screening, medical camp, and door to door survey at a Sub-Centre Faqeer Gujree, a tribal area located in the lap of mountainous ranges of Mahadev, just 25 km's from Srinagar, the summer capital of Jammu \& Kashmir.

\section{SUBJECTS AND METHODS}

This paper is based on the data which was collected as a part of the door to door survey cum health camp which was conducted by the department of community medicine in collaboration with National sample survey (NSS) in the field practice area of Government Medical College, Srinagar. With an intention to organize the health camp for the tribal population, Sub-Centre Faqeer Gujree was selected purposively so as to evaluate the health standards of the tribal population in particular. Sub-Centre Faqeer Gujree has a total population of 1900 individuals and it lies in close proximity to district Srinagar, approximately 1500 meters above sea level, in the lap of mountainous range of Mahadev and just 25 kilometres from Government Medical College, Srinagar.

This cross-sectional study started with micro planning in the Department of Community Medicine, Government Medical College, Srinagar followed by assigning job assessments to various health professional according to the plan. Ethical clearance was obtained from the institutional ethical committee and institutional Head was informed about the survey. In the first step, the village heads were informed about the door to door survey and health camp, who in turn informed the community members. A fixed date for the door to door survey and health camp was communicated to the village heads. All the households gave consent to be part of the survey. Finally on 21st March 2016 door to door survey was conducted in the adjoining areas of the Sub-Centre by postgraduate scholars, intern doctors and pre-final students of the department of community medicine, Government Medical College, Srinagar. A total of 1696 people participated in the house to house survey cum health camp. The survey continued for 3 days i.e: till 23rd March 2016. Data was collected on the predesigned proforma after taking informed consent from the family members. Demographic characteristics include name, age, sex, socioeconomic status, number of eligible couples in the family, use of contraceptive by any family member, number of under five children in the family, immunization status of all the family members, antenatal facilities availed by pregnant women in the family, status of overcrowding, general housing standards, availability of safe and whole some water, and sanitation methods used by individual houses were the variables included in the proforma. On 24th March 2016, a health camp was organized at the Sub-Centre Faqeer Gujree in which most of the community members participated. Qualified doctors examined the community members and provided free treatment for their ailments with the provision of free medicines. The whole survey was conducted under the strict supervision of Head, Department of Community Medicine, GMC, Srinagar.

\section{RESULTS}

Socio-demographic characteristics of the community subject's shows male predominant population with men outnumber women by a ratio of 89 women to 100 men. $57 \%$ of the population is in the adult age group. Among the total households (320), most are joint families with $100 \%$ nonvegetarian diet pattern see in the community. $40 \%$ of the population is illiterate and only $4 \%$ individuals having acquired education above higher secondary. $90 \%$ of the total households belong to upper lower to upper-middle-class socioeconomic status. $70 \%$ of the community households have the provision of safe drinking water, $>80 \%$ have smoking vent in the kitchen and $>90 \%$ population use sanitary latrine for excreta disposal. Prevalence of Smoking behaviour was observed in $14.39 \%$ community population [Table 1].

The community has 247 eligible couples with 23 pregnant women. Total births in the year 2016 were $40.30 \%$ of the population uses contraceptive methods for birth spacing with $100 \%$ immunization coverage in the area. The crude death rate of the area is 4.71 per 1000 population and infant mortality rate is 50.00 per 1000 live births with 9.83 per 1000 population as hospitalization ratio.[Table 2]

\section{DISCUSSION}

The present paper discusses the door to door survey cum health camp which was organized by the department of community medicine, government medical college, Srinagar. The survey cum health camp was one of its kinds as it solely concentrated on the tribal population, their demographic attributes and health indicators in particular. As we know that the tribal community has a distinct ethnic, traditional \& cultural identity, distinctive language, they are economically 
backward and live in seclusion governed by their own social norm and largely having a self-contained economy. There is the probability of underlying health problems in the tribal community which may be due to socio-cultural norms of practicing ancient heath practices, use of herbal medicines, taboos \& superstition. Environmental conditions like forest dwelling may pose a risk of vector-borne diseases. Tribal people are reluctant to adapt maternal and child health services, Nutritional problems are common and there is inaccessibility to safe drinking water and sanitation. The present study was conducted in a tribal area which happens to be the field practice area of the department of community medicine, government medical college. The area has a total population of 1696 individuals with 895 men and 801 women with a male-female ratio of 894 females to 1000 men, which is far behind than the national figures.[4] The age structure of the tribal population is on par with the national figures.[5] Most of the household's live in nuclear families and half of the tribal population is illiterate, the literacy rate of the tribal community is far below than the state and national figures, which is an alarming issue and needs to be looked after in future researches. Sanitation and safe drinking water plays a vital role in maintaining good health of the people. In our study, $70 \%$ of the tribal population had access to the safe drinking water and more than $90 \%$ use the sanitary latrine, still, these figures are not compromising and a threat of gastroenteritis or hepatitis outbreak will continue for the future until proper measures by the government authorities will be taken.

The health care services provided to the tribal community is another dimension that will determine the quality of health among the population, and indirectly determine the acceptability of health care services among them. The presence of a sub-centre in the tribal community along with the allocation of the local ASHAs has significantly contributed to the acceptance of the health services by the tribal community. About $30 \%$ of the population is using contraceptive methods for child spacing which shows the acceptability of the health services by the tribal population and indirectly determines the role of ASHA's in counselling people for such services.

Constrained by data, we have considered three health indicators namely infant mortality rate, maternal mortality rate, and crude death rate. The infant mortality rate of the study area is 50 per 1000 while of the $J \& \mathrm{~K}$ state is 34 and India are 39 per 1000 respectively.[7] There was no recorded death of any mother in the year 2016 showing better maternal and child health delivery services in the area. The crude death rate of the tribal population for the year 2016 was 4.71 per 1000, better than the state and national figures.[7] The house to house survey cum health camp was organized with the view to foresee the health status of the tribal community and the progress of the health delivery services provided by the
Sub-Centre which is located in the close vicinity. The authors have following recommendations for the policy makers for the said tribal community. An adequate number of schools should be built in the area and people should be encouraged to admit their children in them. Local leaders should facilitate and encourage swachh bharat abhiyan and promote the building of latrines. Health education about personal hygiene and provision of safe drinking water should be given to people. Locals should be encouraged to build houses according to housing standards.

\section{CONCLUSION}

Door to door surveys is a good method to reach the tribal community in particular and such surveys should be carried out every year to determine the health status and health care delivery services provided to the tribal community. These surveys acknowledge health authorities and policy makers about the use of health care facilities by the tribal population and help to oversee the barriers in-between tribal community. Further research is warned in future to study different socio-cultural aspects prevailing in the tribal community which acts as a barriers from seeking Health for all behaviour.

\section{ACKNOWLEDGEMENT}

Authors acknowledge the immense help received from the scholars whose articles are cited and included in references of this manuscript. The authors are also grateful to authors / editors / publishers of all those articles, journals and books from where the literature for this article has been reviewed and discussed.

\section{REFERENCES}

1. Indian Public Health Standards (IPHS) Guidelines for Sub-Centres 2012

2. The value of conducting door-to-door surveys Hillier A, Cannuscio C, Griffin L, Thomas N, Glanz K International Journal of Social Research Methodology, vol. 17, issue April (2014) pp. 285-302

3. PANIGRAHI, Sandeep Kumar; PADHI, Asutosh. Maternity Waiting Home - A light of hope for pregnant women in tribal areas? Annals of community Health, [S.1.], v. 2, n. 3, p. 2-3, sep. 2014.

4. Available at: http://www.indiaonlinepages.com/population/sexratio-of-india.html[Accessed on 02-03-2017 01:33:20]

5. Available at: http://www.indexmundi.com/india/age_structure. html[Accessed on 01-03-2017 03:15:21]

6. Available at: http://www.census2011.co.in [Accessed on 01-032017 05:30:24]

7. Available at: http://www.censusindia.gov.in/vital statistics/ SRS_Bulletin_2014.pdf

Accessed on 03-03-2017 15:34:34 
Table 1: Socio-demography characteristics of Tribal Community Population

\begin{tabular}{|c|c|c|}
\hline Variable & Frequency & Percentage (\%) \\
\hline Gender & & \\
\hline Male & 895 & 47.2 \\
\hline Female & 801 & 52.8 \\
\hline Male: Female Ratio & 894 Femal & es to 1000 Males \\
\hline Age in Years & & \\
\hline $0-1$ & 53 & 3.12 \\
\hline $1-5$ & 189 & 11.14 \\
\hline $5^{-19}$ & 496 & 29.24 \\
\hline $20-45$ & 684 & 40.33 \\
\hline$>45$ & 274 & 16.15 \\
\hline Total Households & 320 & - \\
\hline Family Type & & \\
\hline Joint & 13 & 4.06 \\
\hline Nuclear & 307 & 95.93 \\
\hline Education Status & & \\
\hline Not Applicable & 185 & 10.91 \\
\hline Illiterate & 700 & 41.29 \\
\hline Middle School & 540 & 31.85 \\
\hline Secondary School & 213 & 12.56 \\
\hline Higher Secondary & 42 & 2.47 \\
\hline Graduate & 14 & 0.82 \\
\hline Post Graduate & 1 & 0.05 \\
\hline Socio-Economic Statu & & \\
\hline Upper & 5 & 1.56 \\
\hline Upper Middle & 44 & 13.75 \\
\hline Lower Middle & 153 & 48.81 \\
\hline Upper Lower & 95 & 29.68 \\
\hline Lower & 23 & 7.18 \\
\hline $\begin{array}{l}\text { Provision of Safe Drin } \\
\text { water }\end{array}$ & & \\
\hline Present & $224 / 320$ & 70.00 \\
\hline Absent & $96 / 320$ & 30.00 \\
\hline Smoking vent in Kitch & & \\
\hline Present & $263 / 320$ & 82.18 \\
\hline Absent & $57 / 320$ & 17.81 \\
\hline Use of Sanitary Latrine & $296 / 320$ & 92.50 \\
\hline
\end{tabular}

Table 2: Health Indicators of the Tribal community Population [ANC: Antenatal Care]

\begin{tabular}{lcc} 
Variables & Frequency & Percentage (\%) \\
Pregnant Women & $23 / 801$ & 2.87 \\
Eligible Couples & $247 / 1696$ & 14.56 \\
Contraceptive Use & $532 / 1696$ & 31.4 \\
Immunization Status & & \\
Not Complete & 242 & 14.26 \\
Complete & 1454 & 85.73 \\
ANC facility Availed & $122 / 801$ & 15.23 \\
Total Births in 2016 & 40 & - \\
Infant Mortality Rate & 2 & 50 per 1000 \\
Maternal Mortality Rate & 0 & 0 \\
Crude Death Rate & 8 & 4.71 per 10oo \\
\hline
\end{tabular}

